\title{
Influenza A triggered status asthmaticus requiring emergency ECMO
}

\author{
F. Guarracino1, M. Stefani1, P. Maremmani2, M. Corini2, S. Pini2, \\ C. Tascini 3 , F. Menichetti3, N. Ambrosino 4
}

\begin{abstract}
Influenza A triggered status asthmaticus requiring emergency ECMO. F. Guarracino, M. Stefani, P. Maremmani, M. Corini, S. Pini, C. Tascini, F. Menichetti, N. Ambrosino.

We describe a case of acute respiratory failure due to severe pneumonia triggered by the influenza A virus, rapidly evolving into a refractory status asthmaticus requiring emergent ECMO assistance, in order to facilitate the clinical management of patients suffering from this
\end{abstract}

rare but life-threatening condition. This case report demonstrates that infection with influenza $A$ virus can present with severe pneumonia and status asthmaticus refractory to medical and ventilatory treatment. When medical treatment and mechanical ventilation fail, extracorporeal membrane oxygenation therapy should not be delayed as it will avoid injury resulting from inadequate mechanical ventilation and lung hyperinflation. Monaldi Arch Chest Dis 2010; 73: 4, 162-165.

Keywords: Influenza A, Asthma, Status asthmaticus, Acute respiratory failure, ECMO, Mechanical ventilation.

${ }^{1}$ Cardiothoracic Intensive Care Medicine,

2 Intensive Care Unit

3 Infectious Disease Unit,

4 Pulmonary Unit; Azienda Ospedaliera Universitaria Pisana, Pisa, Italy.

Correspondence: Dr. Fabio Guarracino, Cardiothoracic Intensive Care, Azienda Ospedaliera Universitaria Pisana, Via Paradisa 2, 56123 Pisa, Italy; e-mail: fabiodoc64@hotmail.com

\section{Introduction}

In December 2009 most influenza cases in Europe were caused by influenza A H1N1 virus. The infection presented with usual influenza symptoms such as cold, cough, fever and asthenia in the majority of cases. However in young adults and children occasionally an acute respiratory distress was the first presentation requiring intensive care treatment. Usually early antiviral treatment has proved to be effective, but in a minority of patients with respiratory distress mechanical ventilation and advanced extracorporeal support is needed.

Influenza A presentation with near fatal status asthmaticus has never been reported until now, although history of asthma is considered to be a risk factor for complicated influenza A course. We report on a patient with influenza A triggered status asthmaticus and severe pneumonia unresponsive to medical and ventilatory treatment, in whom prompt application of extracorporeal lung assistance proved life saving.

\section{Case report}

A 44 year old man, whose written informed consent to the scientific use of anonymous clinical data was obtained upon hospital discharge, was admitted to the emergency department (ED) due to the sudden onset of cough and dyspnoea. Despite a personal history of asthma attacks, and no histori- cal or spirometric feature of COPD, no specific long-term therapy had been initiated. Symptoms of cold, cough and fever were reported 20 days before ED admission. At admission the patient suffered from respiratory distress, and the clinical exam showed severe bronchospasm, use of accessory muscles, central cyanosis and tachycardia. Body temperature was $37.3 \mathrm{C}^{\circ}$. On the basis of age and predisposing condition (asthma) a H1N1 influenza A was suspected. Chest X-Ray showed signs of pneumonia, hyperinflation, with mild atelectasis on the left lung basis (figure 1). Laboratory data including chemistry were within normal limits but creatine phosphokinase (CPK) which was slightly elevated (550 U/L), whereas blood count showed neutrophilia and lymphopenia. ECG showed sinus tachycardia with heart rate of $140 \mathrm{bpm}$. A pharyngeal swab was taken for H1N1 test using real-time RT-PCR (SuperScript ${ }^{\mathrm{TM}}$ III Platinum ${ }^{\circledR}$ One-Step Quantitative Kit, Invitrogen Ltd, Paisley, UK).

Despite prompt high flow $\mathrm{O}_{2}$ therapy and intravenous steroids, severe arterial desaturation and respiratory distress persisted and even worsened without any clinical improvement. Therefore the patient underwent tracheal intubation and mechanical ventilation and was transferred to the intensive care unit. Initial ventilator settings were pressurecontrolled ventilation at a rate of $8 / \mathrm{bpm}$, positive end-expiratory pressure $5 \mathrm{~cm} \mathrm{H}_{2} \mathrm{O}$, inspiratory pressure $25 \mathrm{~cm} \mathrm{H}_{2} \mathrm{O}$ and inspiratory/expiratory ratio (I:E ratio) 1:5. Inspired fraction of oxygen was 


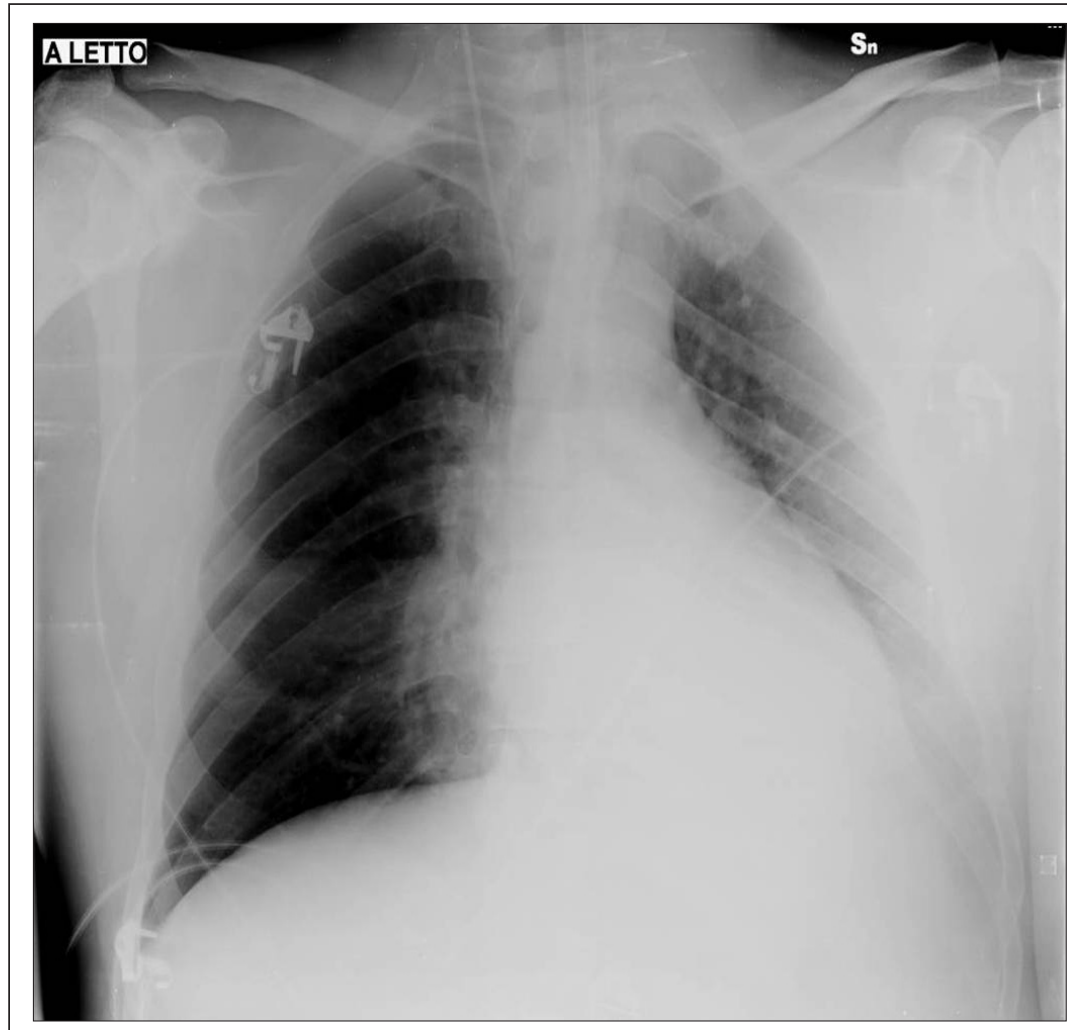

Fig. 1. - Chest x-ray at admission showing signs of pneumonia, lung hyperinflation and mild atelectasis on the left lung basis.

initially 0.5 . Low tidal volume ventilation of 320 $\mathrm{ml}(4 \mathrm{ml} / \mathrm{kg})$ required inspiratory pressures of up to $60 \mathrm{~cm} \mathrm{H}_{2} \mathrm{O}$. An arterial blood gas analysis showed $\mathrm{pH} 6.83, \mathrm{PaCO}_{2} 103$ torr $(13.73 \mathrm{kPa})$, and $\mathrm{PaO}_{2} / \mathrm{FIO}_{2} 100$.

Despite repeated inhaled bronchodilators and high dose steroids, intravenous muscle relaxants, salbutamol and aminophylline, arterial blood gas analysis showed worsening hypercapnia $(\mathrm{pH} 7.0$, $\mathrm{PaCO}_{2} 132$ torr $(17.6 \mathrm{kPa}), \mathrm{PaO}_{2} / \mathrm{FIO}_{2} 128.3$ ). Isoflurane $/ \mathrm{O}_{2}$ ventilation was then commenced with the aim of reducing airways resistance, however the clinical situation did not vary; lung resistance and compliance remained poor, with required high airway pressure leading to hemodynamic impairment.

Approximately 5 hours after admission to the intensive care unit, due to the persistence of the severe and unresponsive respiratory condition, a decision was made to employ extracorporeal lung assistance with extracorporeal membrane oxygenation (ECMO) system. A polyurethane catheter was inserted into the right atrium via the right femoral vein for blood drainage using the percutaneous Seldinger technique. An additional catheter was inserted, again using the percutaneous Seldinger technique, into the superior vena cava through the right internal jugular vein for blood return, in order to establish a veno-venous ECMO. Heparin was administered intravenously in order to maintain an $\mathrm{ACT}>160 \mathrm{sec}$ during ECMO assistance.

The ECMO assistance was commenced with blood flow at about $5 \mathrm{~L} /$ minute, a fresh gas flow of $8 \mathrm{~L} /$ minute and $\mathrm{FiO}_{2}$ of 0.1 . and then adjusted to maintain a $\mathrm{PaCO}_{2}$ between 40 and 45 torr $(5,33$ - 6
$\mathrm{kPa}$ ) and arterial $\mathrm{O}_{2}$ saturation $>92 \%$. This enabled oxygenation to be maintained even at dramatically reduced mechanical ventilation settings. The patient was maintained with protective ventilation at mechanical respiratory rate of 8 breaths per minute, PEEP $10 \mathrm{~cm}$ $\mathrm{H}_{2} \mathrm{O}$ and peak inspiratory pressure $25 \mathrm{~cm} \mathrm{H}_{2} \mathrm{O}$. These parameters led to a tidal volume of $190 \pm 20 \mathrm{ml}$, which slowly increased over the next 48 hours.

Non-invasive monitoring with Vigileo system showed increased cardiac output $(6.8 \mathrm{l} / \mathrm{min})$ and reduced systemic vascular resistances $\left(670\right.$ dyn $\left.\cdot s / \mathrm{cm}^{5}\right)$ requiring low dose noradrenaline to maintain a MAP >65 $\mathrm{mmHg}$.

Although the pharyngeal swab was negative for H1N1 using realtime RT-PCR, antiviral treatment with oseltamivir $150 \mathrm{mg}$ twice a day was started and maintained for five days, and serum test was performed which was positive for influenza A. No infectious agent was isolated either from bronchoalveolar lavage or from blood. Tests of the urine for legionella and $S$. pneumoniae antigens were negative.

Three days after ICU admission alveolar ventilation improved $\left(\mathrm{PaCO}_{2} 39\right.$ torr $(5.2 \mathrm{kPa}), \mathrm{PaO}_{2} /$ $\mathrm{FiO}_{2} 220$, pH 7.41, with peak inspiratory pressure $28 \mathrm{~cm} \mathrm{H}_{2} \mathrm{O}$, tidal volume $620 \mathrm{ml}$, PEEP $4 \mathrm{~cm}$ $\mathrm{H}_{2} \mathrm{O}$ ), and the patient was weaned from ECMO. There were no ECMO related complications, and the patient was weaned from the vasoactive drugs on the following day.

The patient was extubated 5 days after admission, transferred to the Pulmonary Unit on day 8 and discharged home on day 15 with full oral antiasthma therapy.

\section{Discussion}

Despite our case not being unique as regards the H1N1 virus infection and severe asthma attack [1-3], to our knowledge this is the first report on the presentation of influenza A with dramatic status asthmaticus. In our patient pharyngeal test for influenza A H1N1 type was negative probably because the viral infection had occurred 20 days previous. The serology did not allow possibility of making a distinction among the influenza A subtypes, but several factors consisting in the epidemiology (in the same period almost $100 \%$ of influenza cases in our region [4] were due to H1N1 virus), the patient's characteristics (asthma), the severity of presentation and the fast response to antiviral treatment led us to suspect the new influenza to be the cause of such a dramatic clinical scenario.

Recent literature reports acute respiratory failure as a possible presentation of influenza $\mathrm{A}$ infec- 
tion specially in young adults, with severe respiratory distress requiring intensive care treatment [5-8].

The association between respiratory infections and acute asthma exacerbation has been reported with lower incidence in adult patients compared to children $[9,10]$ admitted to hospital with acute exacerbation of asthma. A lower rate of asthma exacerbation from such infections in adults can be attributed to the delayed presentation of adults for management, as in our case, and the more rapid clearing of viruses, which lead to increased difficulty in isolation of viruses in adults.

In refractory asthma, when aggressive treatment with nebulised or intravenous beta- 2 agonists, subcutaneous epinephrine, nebulised anticholinergics, intravenous corticosteroids, intravenous aminophylline and magnesium sulphate do not succeed, patients can be supported by mechanical ventilation to correct hypoxemia and hypercapnia. Despite, we routinely use NIV as a means of avoiding intubation, given the patient's severe clinical conditions we preferred not to unduly delay intubation. However positive pressure ventilation with high inspiratory pressures can cause barotraumas and volutrauma and can result in a permanent deterioration of pulmonary function. For these reasons ECMO, although costly and invasive, can be an effective treatment in selected patients, able to shift them from decompensated to compensated status asthmaticus. ECMO can only be regarded as a bridge to recovery of pulmonary function, allowing the lungs to rest so preventing complications related to aggressive and damaging mechanical ventilation.

Recently, data from International ECLS Registry on ECMO applied to treat status asthmaticus between 1996 and 2006 has been retrospectively analysed [11]. Of 2,127 adult cases reported to the ELSO registry in the studied period, 1,257 were adult respiratory failure ECMO cases. Of these 1,257 cases, asthma was the primary indication to ECMO in only 24 patients. In those patients ECMO was veno-venous in the majority of cases, its duration was shorter if compared to other indications, and was effective in treating the decompensated respiratory function. Outcome data from these patients revealed that ECMO for status asthmaticus is associated with a favourable survival rate (83.4\% to hospital discharge) compared to other ECMO indications. However the complications rate in the asthmatic group seemed to be comparable with other adult ECMO indications, suggesting that a shorter duration of ECMO, as in asthmatic patients, does not reduce the number of complications.

Influenza A $\mathrm{H} 1 \mathrm{~N} 1$ respiratory distress is relatively frequent among patients with a history of asthma accounting for $28 \%$ hospitalised for severe lung diseases [12]. In fatal cases of influenza $\mathrm{H} 1 \mathrm{~N} 1$ pathological findings were similar to those found in fatal cases of avian influenza H5N1 [13]. In such infections viral replication in the lower respiratory tract is believed to trigger cytokine deregulation [14], therefore, although the pathogenesis of respiratory failure in patients with 2009 influenza A H1N1 infection is not defined, it may be similar to that of $\mathrm{H} 5 \mathrm{~N} 1$, and the modified cytokines imbalance may be the initial stimulus to asthma deterioration.

Despite the need for amines to increase arterial blood pressure, the patient did not fullfil the criteria for severe sepsis [15]. We used high dose steroid therapy. According to the literature reports more than $34 \%$ of H1N1-virus severe infections were treated with corticosteroids. This data together with other reports may suggest a possible lifesaving use of corticosteroids at a stress dose in severely ill patients with an H1N1-virus infection that is not responding to the most advanced treatments [16]. Corticosteroid therapy has been used in varied doses for sepsis and related syndromes for more than 50 years, with no clear benefit on mortality. Since 1998, studies have consistently used prolonged low-dose corticosteroid therapy, and analysis of this subgroup suggests a beneficial drug effect on short-term mortality $[17,18]$.

We conclude that a high suspicious of influenza A virus should always be maintained in abrupt acute respiratory distress presenting with severe pneumonia and asthma exacerbation, therefore prompting immediate antiviral treatment, and that ECMO can be a life saving treatment in influenza A triggered status asthmaticus if its application is not delayed when drugs administration and mechanical ventilation fail.

\section{References}

1. Sandrock C. Novel H1N1 influenza: the impact on respiratory disease and the larger healthcare system. $E x$ pert Rev Respir Med 2009; 3: 335-338.

2. Sposato B, Croci L, Canneti E, et al. Influenza A H1N1 and severe asthma exacerbation. Eur Rev Med Pharmacol Sci 2010; 14: 487-490.

3. Estella A. Bronchoalveolar lavage for pandemic influenza A (H1N1)v pneumonia in critically ill patients. Intensive Care Med 2010; 36: 1976-1977.

4. http: //www.iss.it/iflu

5. Ramsey CD, Funk D, Miller RR 3rd, Kumar A. Ventilator management for hypoxemic respiratory failure attributable to H1N1 novel swine origin influenza virus. Crit Care Med 2010; 38 (4 Suppl): e58-65.

6. Patel M, Dennis A, Flutter C, Khan Z. Pandemic (H1N1) 2009 influenza. Br J Anaesth 2010; 104: 128142.

7. Freed DH, Henzler D, White CW, et al. The Canadian Critical Care Trials Group. Extracorporeal lung support for patients who had severe respiratory failure secondary to influenza A (H1N1) 2009 infection in Canada. Can J Anaesth 2010; 57: 240-247.

8. Australia and New Zealand Extracorporeal Membrane Oxygenation (ANZ ECMO) Influenza Investigators, Davies A, Jones D, Bailey M, et al. Extracorporeal Membrane Oxygenation for 2009 Influenza A(H1N1) Acute Respiratory Distress Syndrome. JAMA 2009; 302: 1888-1895.

9. Fallot A. Respiratory distress. Pediatr Ann 2005; 34: 885-891.

10. Contoli M, Marku B, Conti V, Saturni S, Caramori G, Papi A. Viral infections in exacerbations of asthma and chronic obstructive pulmonary disease. Minerva Med 2009; 100: 467-78. 
11. Mikkelsen ME, Woo YJ, Sager JS, Fuchs SB, Christie JD. Outcomes Using extracorporeal Life Support for Adult Respiratory Failure due to Status Asthmaticus. ASAIO Journal 2009; 55: 47-52.

12. Jain S, Kamimoto L, Bramley AM, et al. Hospitalized patients with 2009 H1N1 Influenza in the United States, april-june 2009. N Eng J Med 2009; 361: 1935-1944.

13. Soto-Abram MV, Soriano Rosas J, Diaz-Quinonez A, et al. Pathological changes associated with $2009 \mathrm{H} 1 \mathrm{~N} 1$ virus. N Eng J Med 2009; 361: 2001-2003.

14. De Jong MD, Simmons CP, Thanh TT, et al. Fatal outcome of human influenza A (H5N1) is associated with high viral load and hypercytokinemia. Nat Med 2006; 12: 1203-1207.

15. Levy MM, Fink MP, Marshall JC, Abraham E, Angus
D, Cook D, Cohen J, Opal SM, Vincent JL, Ramsay G; SCCM/ESICM/ACCP/ATS/SIS. 2001 SCCM/ESICM/ ACCP/ATS/SIS International Sepsis Definitions Conference. Crit Care Med 2003; 31: 1250-1256.

16. Confalonieri M, Cifaldi R, Dreas L, Viviani M, Biolo M, Gabrielli M. Methylprednisolone infusion for lifethreatening H1N1-virus infection. Ther Adv Respir Dis 2010; 4: 233-237

17. Annane D, Bellissant E, Bollaert PE, et al. Corticosteroids in the treatment of severe sepsis and septic shock in adults: a systematic review. JAMA 2009; 30: 2362-2375.

18. Confalonieri M, Urbino R, Potena A, et al. Hydrocortisone infusion for severe community-acquired pneumonia: a preliminary randomized study. Am J Respir Crit Care Med 2005; 171: 242-248.

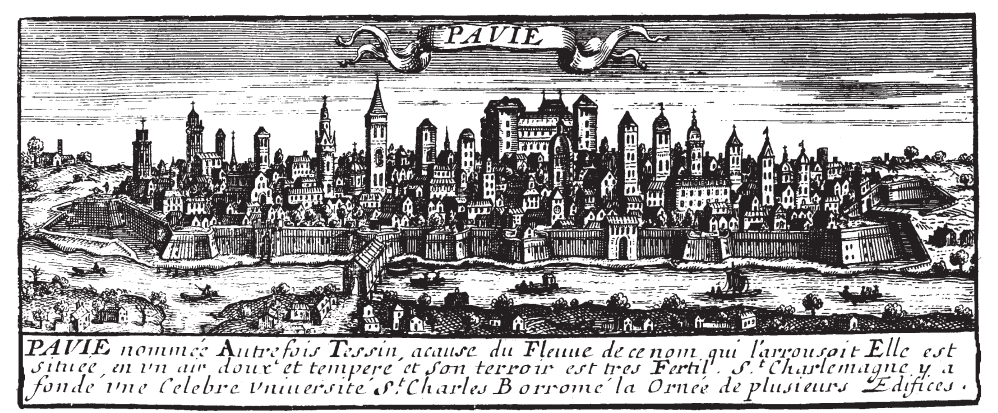

